\title{
Polymorphous Adenocarcinoma of Lacrimal Gland: A Rare Case Report
}

\author{
Md Ali Osama ${ }^{1}$, Seema Rao ${ }^{1 *}$ and A K Grover ${ }^{2}$ \\ 'Department of Histopathology, Sir Ganga Ram Hospital, New Delhi, India \\ ${ }^{2}$ Department of Ophthalmology, Sir Ganga Ram Hospital, New Delhi, India
}

\begin{abstract}
Polymorphous adenocarcinoma is a slow growing malignant tumor of minor salivary glands. The most common location of these tumors is palate, buccal mucosa, upper lip, floor of mouth and retromolar region. This malignant neoplasm is characterized by cytological uniformity, architectural diversity and infiltrative growth pattern. This is a case report of polymorphous adenocarcinoma occurring in lacrimal gland. They are seldom reported in this location and propose unique diagnostic challenges.
\end{abstract}

Keywords: Immunohistochemistry, Lacrimal Gland, Polymorphous Adenocarcinoma (Pac).

\section{Introduction}

Lacrimal gland tumors are rare and represent only $10 \%$ of the space occupying orbital lesions ${ }^{[1]}$. Epithelial tumors constitute about one third of lacrimal gland tumors, out of which half of the tumors are malignant with majority being adenoid cystic carcinoma. Polymorphous low-grade adenocarcinoma (PLGA) is a malignant epithelial tumor of salivary gland. It is slow growing and indolent in nature. According to the recent WHO Classification of Salivary Gland Tumors (2017), the new designation of this tumor is Polymorphous adenocarcinoma (PAC). This tumor has an unpredictable behavior and has a tendency for recurrence. ${ }^{[2]}$. These tumors are characterized by cytological uniformity, morphological diversity and an infiltrative growth pattern. This is one tumor which is poorly understood, infrequently encountered and underdiagnosed, especially in an uncommon location.

\section{Case History}

A 43-year-old male patient presented with complaints of double vision and proptosis of left eye for the last 8 months. Examination revealed a visual acuity of 6/9 OD and $6 / 6$ OS and $3 \mathrm{~mm}$ proptosis as measured by Hertel's exopthalmometer. There was diplopia in dextro depression, confirmed by diplopia charting. There was presence of conjunctival hyperemia on the temporal aspect. A mass was present in the superotemporal area of orbit. Computed tomography image revealed an ill-defined mass and gave the possibility of orbital lymphoma or pseudotumor. On PET scan, no avidity was seen anywhere else in the body. Fine needle aspiration was done elsewhere and was inconclusive. Hence, a transconjunctival biopsy and a subsequent orbital mass resection was done by lateral orbitotomy and sent for histopathological examination. Histopathological study revealed a tumor that was composed of uniformly looking cells arranged in cords/ single files, sheets, groups, singly dispersed tumor cells as well as focal cribriform and glandular pattern [Figure 1a-c]. Neoplastic cells were large, oval to polygonal with central to eccentric nuclei, small nucleoli and abundant finely granular cytoplasm. Few signet ring cells were also present. The tumor was diffusely infiltrating the orbital soft tissue, lacrimal gland and extraocular muscles [Figure $1 \mathrm{~d}$ and e]. Tumor had a dense fibrous stroma with focal storiform pattern. There was prominent perineural and intraneural infiltration [Figure 1f]. Based on the histologic picture, the possibilities of a primary malignant tumor of lacrimal gland (Polymorphous adenocarcinoma \& Histiocytoid variant of eccrine duct carcinoma), Granular cell tumor or a metastatic malignant tumor were suspected. Accordingly, a panel of immunohistochemical (IHC) markers was applied to derive a final diagnosis [Table 1]. The tumor cells showed a strong positivity for Cytokeratin (CK), CK 7 and Epithelial Membrane Antigen(EMA) which confirmed its epithelial nature of origin [Figure 2a and b]. Vimentin and S-100 were found to be negative thus ruling out Granular cell tumor [Figure 2c]. Panel of markers such as Estrogen Receptor (ER) \& Progesterone Receptor (PR) for breast cancer, Thyroid Transcription Factor (TTF-1) for lung carcinoma, CK20 for colonic cancer, PAX8 \& CD10 for renal cell carcinoma and Prostate Specific Antigen (PSA) for prostatic carcinoma were used which all showed immunonegativity, thus effectively ruling out possibility of metastasis. Ki67 proliferative index was low [Figure 2d].

Based on clinical, radiographic, histopathological and IHC evaluation, a diagnosis of Polymorphous adenocarcinoma 
was rendered. The tumor was surgically excised; however, no radiotherapy was given. The patient had a good recovery and on his last follow up (3 years since surgery) showed no signs of recurrence.

\section{Discussion}

Lacrimal gland tumors are relatively rare and can represent a wide spectrum of differentials ranging from benign epithelial and mesenchymal tumors to carcinomas, sarcomas and lymphomas. The term 'lobular carcinoma' was described by Freedman and Lumerman in 1983 as it has a similar picture to lobular carcinoma of breast ${ }^{[3]}$. Polymorphous low grade adenocarcinoma (PLGA) was first coined in 1984 by Evans and Batsakis and was thought to be an indolent tumor that affects the minor salivary glands of the oral cavity (palate and buccal mucosa) which showed variable morphological appearance and a low grade behavior ${ }^{[4]}$. The mean age of presentation is 54 years $^{[5]}$. In the largest study of 164 cases by Castle et al, this tumor occurred in minor salivary gland with palate being the most common site ${ }^{[6]}$. One of the rare location includes lacrimal gland. Only few case reports of PAC of lacrimal gland have been published in literature so far ${ }^{[7,8]}$ [Table 2].

It is important to differentiate PAC from other lacrimal gland tumors with myoepithelial differentiation, such as pleomorphic adenoma, adenoid cystic carcinoma and histiocytoid variant of eccrine sweat gland carcinoma as well as metastatic tumors especially the ones showing morphology similar to lobular carcinoma breast. PA do not infiltrate the adjacent tissues such as fat, muscle and bone which is characteristic of PAC. Cells of PAC are round to oval and have a bland nuclear chromatin with moderate amount of eosinophilic to clear cytoplasm while the cells of adenoid cystic carcinoma are more basaloid and have small hyperchromatic angulated nuclei. Secondary tumors are rare at this anatomical site and they account less than $1 \%$ of all the malignant tumors of lacrimal gland. Small biopsies from PAC may represent a single architectural pattern and thus can cause diagnostic challenge and possible misdiagnosis. Large biopsies and resection specimens are thus better to evaluate the typical morphological diversity and the invasive borders. The current case also showed uniform looking cells with diverse architectural patterns and invasive borders. Many studies have tried to evaluate IHC markers specific for PAC which can be used to differentiate it from other lesions showing similar histologic picture, however with limited success ${ }^{[6,9]}$. Clinical immunoprofiling of PAC shows positivity for panCK and CK7 (in 21/21 cases; 100\%), EMA (in 10/12 cases; $83 \%$ ), CEA (in 21/39 cases; 54\%), S-100 (in 38/39 cases; 97\%) and Vimentin (16/16 cases; 100\%) ${ }^{[6,10,11]}$. Castle et al applied S-100 in 39 cases of PLGA and found

Table 1: Summary of IHC findings of the present case and the possible differentials.

\begin{tabular}{|l|l|l|l|l|l|}
\hline IHC & $\begin{array}{l}\text { Polymorphous } \\
\text { adeno-carcinoma }\end{array}$ & $\begin{array}{l}\text { Histiocytoid variant } \\
\text { of eccrine sweat } \\
\text { gland carcinoma }\end{array}$ & $\begin{array}{l}\text { Granular cell } \\
\text { tumor }\end{array}$ & $\begin{array}{l}\text { Metastatic } \\
\text { carcinoma }\end{array}$ & Present case \\
\hline CK & + & + & - & + & + \\
\hline EMA & + & + & - & + & + \\
\hline CK7 & + & + & - & + & + \\
\hline S-100 & + & + & - & - & + \\
\hline CEA & + & + & + & + & - \\
\hline CD68 & - & + & + & - & - \\
\hline Vimentin & + - & - & +- & - \\
\hline
\end{tabular}

Table 2: Comparison of our study with other studies in literature.

\begin{tabular}{|c|c|c|c|c|c|c|c|c|}
\hline Study & Year & $\begin{array}{l}\text { Number } \\
\text { of cases }\end{array}$ & $\begin{array}{l}\text { Age and } \\
\text { Sex }\end{array}$ & Presentation & $\begin{array}{l}\text { Clinical } \\
\text { Differentials }\end{array}$ & IHC & Treatment & $\begin{array}{l}\text { Follow up } \\
\text { period }\end{array}$ \\
\hline Ni et al [8] & 1992 & 3 & NA & NA & $\begin{array}{l}\text { Adenoid cystic } \\
\text { carcinoma }\end{array}$ & Not Done & NA & NA \\
\hline $\begin{array}{l}\text { Selva D et } \\
\text { al }{ }^{[7]}\end{array}$ & 2004 & 1 & $\begin{array}{l}67 \text { years/ } \\
\text { Male }\end{array}$ & $\begin{array}{l}\text { Proptosis and } \\
\text { conjunctival } \\
\text { hyperemia }\end{array}$ & Abscess & $\begin{array}{l}\text { CK+ } \\
\text { S-100+ }\end{array}$ & Exenteration & 6 years \\
\hline $\begin{array}{l}\text { Present } \\
\text { study }\end{array}$ & 2021 & 1 & $\begin{array}{l}43 \text { years/ } \\
\text { Male }\end{array}$ & $\begin{array}{l}\text { Proptosis and } \\
\text { double vision }\end{array}$ & $\begin{array}{l}\text { Lymphoma or } \\
\text { pseudotumor }\end{array}$ & $\begin{array}{l}\text { CK+ } \\
\text { EMA+ } \\
\text { CK7+ } \\
\text { S-100- }\end{array}$ & $\begin{array}{l}\text { Surgical } \\
\text { excision }\end{array}$ & 3 years \\
\hline
\end{tabular}




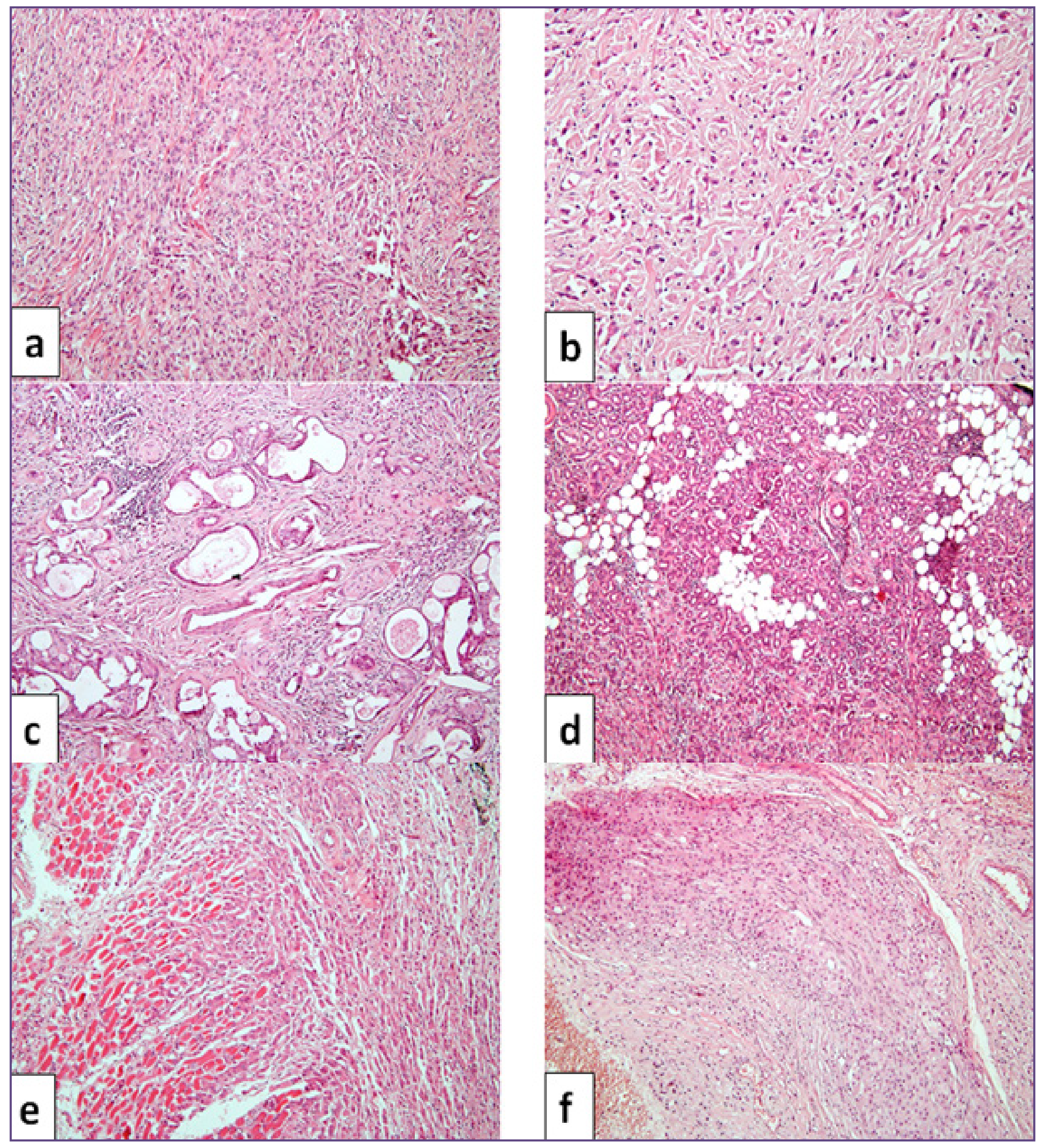

Fig. 1a: Diffusely infiltrative tumor composed of uniformly looking cells arranged in cords/single files, groups and singly dispersed in a fibroblastic stroma (HE 100x). b: Neoplastic cells in cords and scattered singly with central to eccentric nuclei, small nucleoli and abundant finely granular cytoplasm (HE 200x). c: Focal glandular and cribriform arrangement of tumor (HE 100x). d: Diffuse infiltration of tumor into orbital soft tissue and lacrimal gland tissue (HE 100x). e: Tumor infiltrating into the extraocular muscle (HE 100x). f: Perineural and intraneural infiltration by tumor cells (HE 100x). 


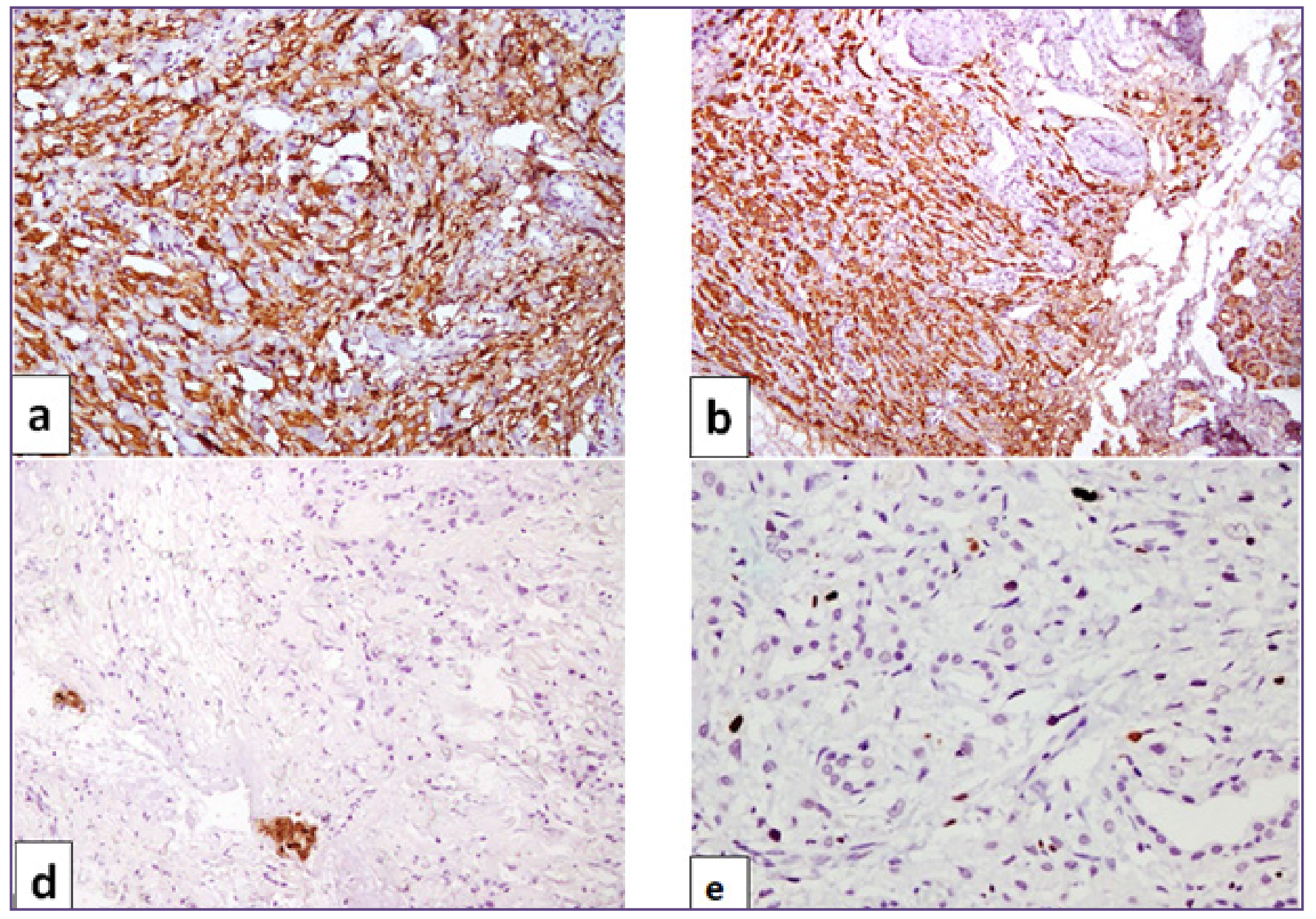

Fig. 2a: CK- Positive (200x). b: CK7 -Positive (100x). c: S-100- Negative (200x). d: Low Ki67\% (200x).

1 case which showed immunonegativity ${ }^{[6]}$. Similar finding was present in our case. IHC panel of PAC vis-à-vis chief differentials is discussed in Table 1.

Secondary tumors are rare at this anatomical site and they account less than $1 \%$ of all the malignant tumors of lacrimal gland. Breast carcinoma is an important primary tumor metastasizing to lacrimal gland ${ }^{[12]}$. Other possible primaries could be from lung, kidney, prostate or gastrointestinal origin. Immunohistochemistry is a valuable tool to distinguish primary and metastatic lacrimal gland neoplasms. As in our case all possible markers for secondary tumors were negative thus ruling out metastasis.

Polymorphous adenocarcinoma has a much better prognosis with low chances of local recurrence and distant metastasis as compared to other salivary adenocarcinomas [3-7]. On the contrary, according to some authors these tumors show an unpredictable behavior and are often diagnosed with widespread infiltration at the presentation ${ }^{[13]}$. Reports of histologic dedifferentiation or transformation to a high grade carcinoma are very rare and have mostly occurred after atleast 13 years of its initial diagnosis as PLGA ${ }^{[13]}$. Hence, the better descriptive term for these lesions is 'Polymorphous adenocarcinoma' as it doesn't tell about the behavior and thus avoids an inappropriate conservative treatment. Surgical excision is considered curative treatment for these tumors. Role of radiotherapy is still unclear. These patients should be on regular follow-up for detecting possible local relapses.

\section{Conclusion}

Only a few reports are available describing Polymorphous adenocarcinoma (PAC) in lacrimal gland/orbit. Recognition of its distinct morphological features in conjunction with IHC can help to diagnose this uncommonly encountered tumor in this location. PAC carries better prognosis than other lacrimal carcinomas. Correct diagnosis is crucial for proper management of the patient.

\section{Funding}

None 


\section{Competing Interests}

None

\section{References}

1. Shields JA, Shields CL, Scartozzi R. Survey of 1264 patients with orbital tumors and simulating lesions: The 2002 Montgomery Lecture, part 1. Ophthalmology. 2004;111:9971008 .

2. Seethala RR, Stenman G. Update from the 4th Edition of the World Health Organization Classification of Head and Neck Tumours: Tumors of the Salivary Gland. Head Neck Pathol. 2017;11:55-67.

3. Freedman PD, Lumerman H. Lobular carcinoma of intraoral minor salivary gland origin. Report of twelve cases. Oral Surg Oral Med Oral Pathol. 1983;56:157-66.

4. Evans HL, Batsakis JG. Polymorphous low-grade adenocarcinoma of minor salivary glands. A study of 14 cases of a distinctive neoplasm. Cancer. 1984;53:935-42.

5. Kimple AJ, Austin GK, Shah RN, et al. Polymorphous lowgrade adenocarcinoma: a case series and determination of recurrence. Laryngoscope. 2014;124:2714-9.

6. Castle JT, Thompson LD, Frommelt RA, Wenig BM, Kessler HP. Polymorphous low grade adenocarcinoma: a clinicopathologic study of 164 cases. Cancer. 1999;86:207-19.
7. Selva D, Davis GJ, Dodd T, Rootman J. Polymorphous low-grade adenocarcinoma of the lacrimal gland. Arch Ophthalmol. 2004;122:915-7.

8. Ni C, Kuo PK, Dryja TP. Histopathological classification of 272 primary epithelial tumors of the lacrimal gland. Chin Med J (Engl). 1992;105:481-5.

9. Darling MR, Schneider JW, Phillips VM. Polymorphous low-grade adenocarcinoma and adenoid cystic carcinoma: a review and comparison of immunohistochemical markers. Oral Oncol. 2002;38:641-5.

10. Meer S, Altini M. CK7+/CK20- immunoexpression profile is typical of salivary gland neoplasia. Histopathology. 2007;51:26-32.

11. Perez-Ordonez B, Linkov I, Huvos AG. Polymorphous lowgrade adenocarcinoma of minor salivary glands: a study of 17 cases with emphasis on cell differentiation. Histopathology. 1998;32:521-9.

12. Verdijk RM, Pecorella I, Mooy CM. The Orbit, Including the Lacrimal Gland and Lacrimal Drainage System. In: Heegaard S., Grossniklaus H. (eds) Eye Pathology. Springer, Berlin, Heidelberg;2015.p.547-731.

13. Chatura KR. Polymorphous low grade adenocarcinoma. J Oral Maxillofac Pathol. 2015;19:77-82.

*Corresponding author:

Dr Seema Rao, Department of Histopathology, Sir Ganga Ram Hospital, New Delhi, India

Phone: +91 9868551374

Email: seemarao1974@yahoo.co.in

Date of Submission $\quad: 12 / 06 / 2021$

Date of Final Revision : 08/08/2021

Date of Acceptance $\quad: \mathbf{1 0} / 08 / 2021$

Financial or other Competing Interests: None.

Date of Publication $\quad: 30 / 08 / 2021$ 